MATEMÁTICA

NAS PROFISSÕES 


\title{
Matemática nas Profissões
}

Copyright (c) 2018 Elisa Fonseca Sena e Silva e Viviane de Oliveira Santos Direitos reservados pela Sociedade Brasileira de Matemática.

A reprodução não autorizada desta publicação, no todo ou em parte, constitui violação de direitos autorais. (Lei 9.610/98)

\section{Sociedade Brasileira de Matemática}

Presidente: Paolo Piccione

Vice-Presidente: Nancy Garcia

Diretores:

\author{
Walcy Santos \\ Gregório Pacelli \\ Marcio Gomes Soares \\ João Xavier
}

\section{Editores}

Hilário Alencar e Marcelo Viana

\section{Assessor Editorial}

Tiago Costa Rocha

Capa, Projeto Gráfico e Editoração

Pablo Diego Regino

\section{Distribuição e vendas}

Sociedade Brasileira de Matemática

Estrada Dona Castorina, 110 Sala 109 - Jardim Botânico

22460-320 Rio de Janeiro RJ

Telefones: (21) 2529-5073 / 2529-5095

http://www.sbm.org.br / email:lojavirtual@sbm.org.br

ISBN 978-85-8337-136-6 


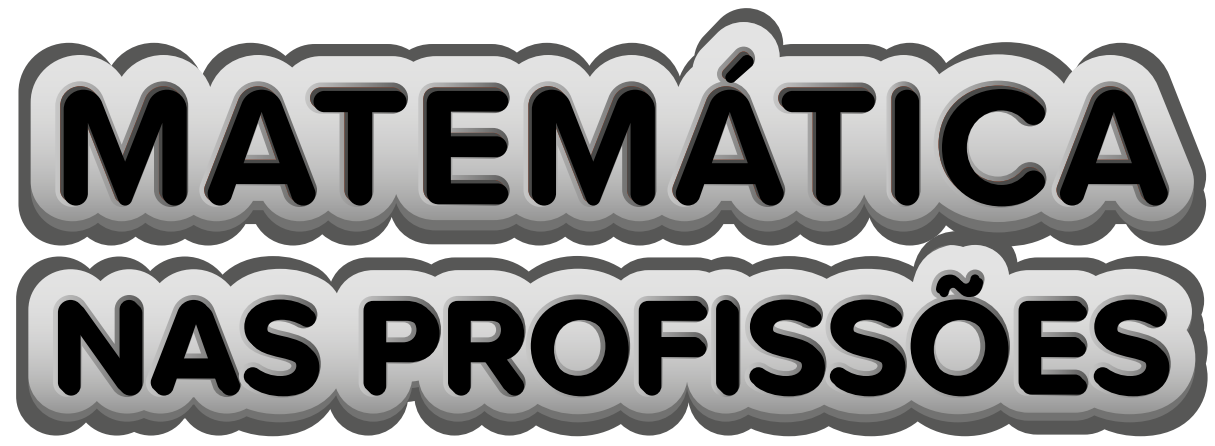

\section{Elisa Fonseca Sena e Silva viviane de Oliveira Santos}

Rio de Janeiro

2018 


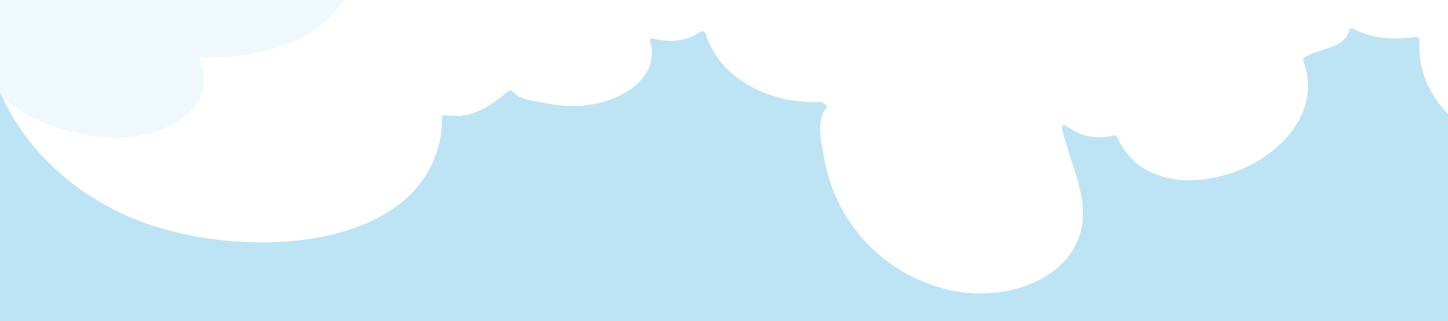




\section{AS AUTORAS}

Elisa Fonseca Sena e Silva é docente do Instituto de Matemática da Universidade Federal de Alagoas (Ufal). Cursou bacharelado e mestrado em Matemática na UFMG e, atualmente, está concluindo seu doutorado em Educação pela Ufal. Desde 2011 trabalha com formação inicial e continuada de professores de matemática, tendo atuado em diversos projetos de extensão voltados para esse público. Foi uma das criadoras do projeto "Sem mais nem menos" em 201\%, do qual segue como subcoordenadora.

Viviane de Oliveira Santos possui doutorado em Educação Matemática pela Universidade Estadual Paulista "Julio de Mesquita Filho" (Unesp) e mestrado em Matemática pela Universidade Federal de Alagoas (Ufal). É docente no Instituto de Matemática da Ufal, coordenadora do Curso de Matemática Licenciatura da Ufal, coordenadora do projeto de extensão "Sem mais nem menos" da Ufal, docente no Mestrado Profissional em Rede Nacional (Profmat), editora-adjunta da Coleção História da Matemática da Sociedade Brasileira de Matemática e líder do Grupo de Pesquisa "História da Matemática e Educação Matemática" da Ufal. Foi vice-coordenadora nacional do Profmat e coordenadora do curso de Licenciatura em Matemática a Distância da Ufal. Tem experiência na área de Matemática, com ênfase em Geometria Diferencial, História da Matemática e Educação Matemática. 


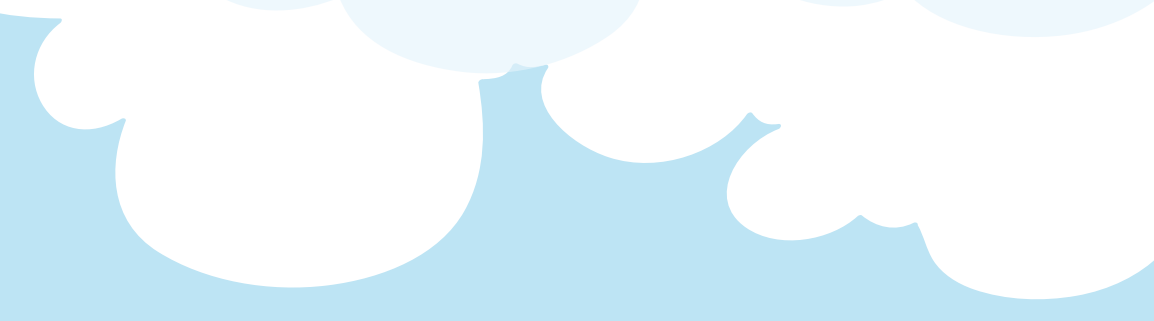




\section{SUMÁRIO}

APRESENTAÇÃO 1

AGRADECIMENTOS 3

COMO JOGAR 5

DESAFIO 1

DESAFIO 2

DESAFIO $3 \quad 9$

DESAFIO 4

DESAFIO 5

DESAFIO 6

DESAFIO 7

DESAFIO 8

DESAFIO 9

DESAFIO $10 \quad 16$

PALAVRAS CRUZADAS 17

CAÇA PALAVRAS 19

ANOTAÇÕES 20

RESPOSTAS 21

REFERÊNCIAS 28 


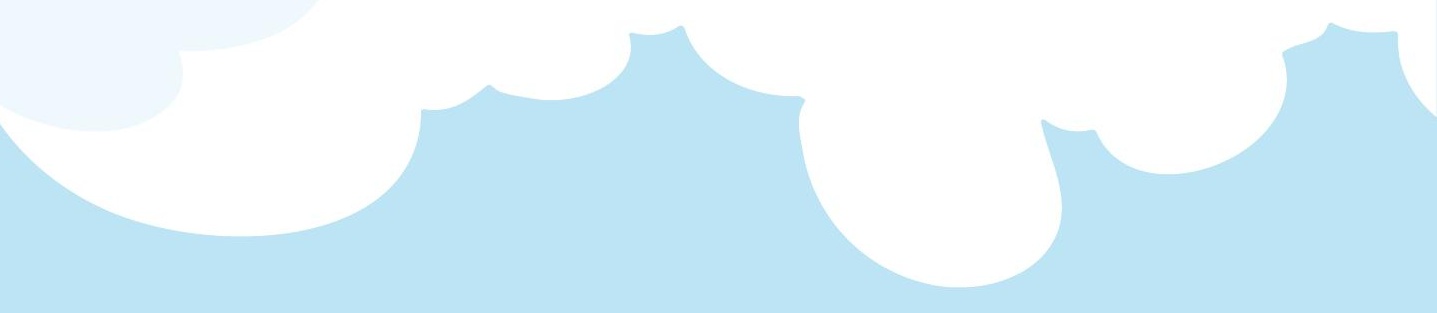




\section{APRESENTAÇÃO}

Este livro contém atividades que exploram a Matemática presente em algumas profissões, composto por dez "Desafios de Lógica”, uma "Palavras Cruzadas" e um "Caça Palavras".

Os "Desafios de Lógica" têm como finalidade aprimorar a leitura e desenvolver o raciocínio lógico dedutivo adormecido no cotidiano escolar. A atividade "Palavras Cruzadas" foi implementada com pequenos enigmas descrevendo cada profissão, objetivando a reflexão a respeito da mesma, e o "Caça Palavras" foi feito a pedido de alunos, como uma atividade mais recreativa.

As atividades expostas foram desenvolvidas durante o projeto de extensão intitulado "Sem mais nem menos", coordenado pelas professoras Viviane Oliveira e Elisa Sena, docentes do Instituto de Matemática da UFAL, e com colaboração da professora da escola em que foi desenvolvido o projeto, Erenilda Albuquerque. O mesmo foi executado com a finalidade de suprir as lacunas existentes entre a matemática exposta na sala de aula e o cotidiano do aluno. Apesar de estar presente em diversas situações do dia a dia, fazendo parte das profissões de um modo geral e sendo identificada até na natureza, a matemática passa despercebida por nossos estudantes e muitas perguntas são feitas durante todo o processo da educação básica: "Para que serve isso? Onde vou usar essa matemática na minha vida?".

As atividades são uma maneira lúdica de desenvolver, através do contato com diferentes profissões, a aprendizagem em Matemática dos estudantes, levando-os a perceber o elo entre prática e teoria, metodologia que deve ser constantemente desenvolvida na prática educacional. Os próprios Parâmetros Curriculares Nacionais (PCNs) indicam que o professor deve deixar claro que a "Matemática também faz parte da vida das pessoas como criação humana, ao mostrar que ela tem sido desenvolvida para dar respostas às necessidades e preocupações de diferentes culturas” (BRASIL, 1998, p. 59).

Por ser a matemática responsável por grandes avanços técnicos e científicos, temos que:

A constatação da sua importância apoia-se no fato de que a Matemática desempenha papel decisivo, pois permite resolver problemas da vida cotidiana, tem muitas aplicações no mundo do 
trabalho e funciona como instrumento essencial para a construção de conhecimentos em outras áreas curriculares. Do mesmo modo, interfere fortemente na formação de capacidades intelectuais, na estruturação do pensamento e na agilização do raciocínio dedutivo do aluno. (BRASIL, 1997, p. 15).

Dessa forma, nos perguntamos quais metodologias devemos então utilizar para que nossos alunos percebam que a matemática não é apenas subjetividade, mas que ela está no nosso dia-a-dia? Pois entendemos que,

[...] a vitalidade da Matemática deve-se também ao fato de que, apesar de seu caráter abstrato, seus conceitos e resultados têm origem no mundo real e encontram muitas aplicações em outras ciências e em inúmeros aspectos práticos da vida diária: na indústria, no comércio e na área tecnológica. Por outro lado, ciências como Física, Química e Astronomia têm na Matemática ferramenta essencial. (BRASIL, 1997, p. 23).

O projeto de extensão foi desenvolvido na Escola Municipal de Ensino Fundamental Padre Pinho, localizada no bairro Cruz das Almas em Maceió-AL, durante o período agosto de 2016 a agosto de $201 \%$, em quatro turmas do $6^{\circ}$ ano e duas turmas do $7^{\circ}$ ano. Contou com o apoio de oito alunos do curso de Matemática Licenciatura da UFAL, entre bolsistas e colaboradores.

A flexibilidade quanto aos assuntos que podem ser abordados é um dos benefícios de todas as atividades presentes no livro. A escolha do tema que nomeia o livro foi feita em função do objetivo do projeto. No entanto, o professor pode alterar os desafios para trabalhar o assunto que é mais interessante para a turma naquele momento, contribuindo para que seja um produto que pode ser adequado para qualquer turma. Além disso, desenvolver a leitura e o raciocínio lógico beneficia o aluno não só na matemática, como nas outras disciplinas. Também podem ser adaptados para outras turmas em contextos diferentes, desde que o professor adeque as atividades à realidade dos seus estudantes.

As atividades são uma maneira lúdica de desenvolver a interpretação dos estudantes e oportunizar o contato com diferentes profissões que estão bastante próximas, sendo possível obter resultados satisfatórios para os envolvidos visto que os alunos percebem o elo entre prática e a teoria, promovendo, assim, a aprendizagem em Matemática. 


\section{AGRADECIMENTOS}

Embora constem nossos nomes como autoras deste livro, por sermos as coordenadoras do projeto de extensão, o mesmo foi produto de todo um trabalho de equipe. Sendo assim, agradecemos:

- à Erenilda Severina da Conceição Albuquerque, que nos acolheu em suas salas de aula, apoiando a execução deste projeto;

- aos nossos bolsistas e colaboradores, por toda dedicação e empenho na realização das suas atividades: Denilson Inácio Lopes da Silva, Elison Antônio dos Santos, Késsia Tatiane Rodrigues dos Santos, Lucas Queiroz Cordeiro de Moura, Maria Jussara da Silva, Nickson Deyvis da Silva, Pedro Henrique Fidelis de Moura Acioli e Wanessa Cavalcanti Oliveira;

- à Pró-Reitoria de Extensão da UFAL, que apoiou o projeto através das bolsas concedidas aos graduandos;

- à direção da Escola Municipal de Ensino Fundamental Padre Pinho, por nos receber de forma tão solícita;

- à Sociedade Brasileira de Matemática por tornar possível esta publicação e todo apoio recebido.

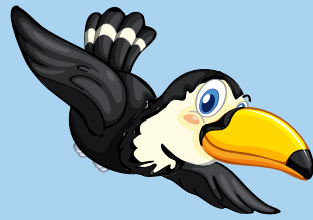




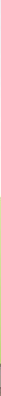




\section{DESAFIO DE LÓGICA. Como preencher o diagrama?}

1. No diagrama, cada quadradinho representa uma frase. O seu trabalho é descobrir, usando as dicas, quais frases são verdadeiras e quais são falsas.

2. Você vai usar seu lápis de cor para colorir os quadradinhos das frases verdadeiras e usar seu lápis de escrever (cinza) para cobrir os quadradinhos das frases falsas.
3. Para cada quadradinho colorido, há na mesma linha e na mesma coluna dois quadradinhos com frases falsas, que precisam pintados de cinza.

4. Agora o diagrama vai estar quase pronto: você só vai precisar comparar as partes coloridas com as partes cinza para concluir a atividade.

\section{EXEMPLO}

Chico e Fabricio são professores. Um dia eles estavam conversando sobre como usam a matemática nas suas aulas. Um deles disse: "Eu uso o plano cartesiano para mostrar as coordenadas geográficas". O outro disse: "Eu uso formas geométricas para poder fazer as bases dos desenhos”. Um deles é professor de geografia e o outro é professor de artes. Siga as pistas para completar o quadro de respostas.

\section{Dica 1:}

O professor de geografia usa o plano cartesiano.

\section{Dica 2:}

Chico é professor de artes.

\section{Dica 3:}

O professor de artes usa figuras geométricas.

\section{Dica 4:}

\section{Fabricio não usa figuras} geométricas.

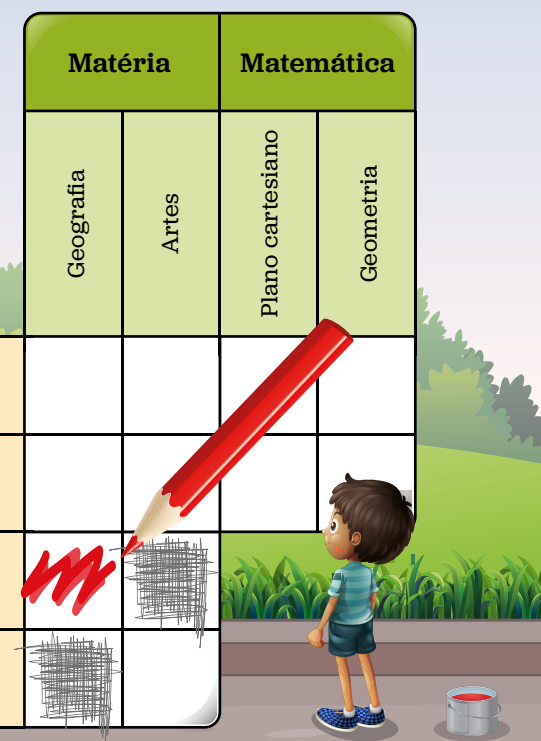

A dica 1 é: o professor de geografia usa o plano cartesiano. Então, o quadradinho de plano cartesiano e geografia é verdadeiro e precisa ser pintado de colorido. Mas o quadradinho plano cartesiano e artes é falso e precisa ser pintado de cinza. O mesmo acontece com o quadradinho geometria e geografia. 

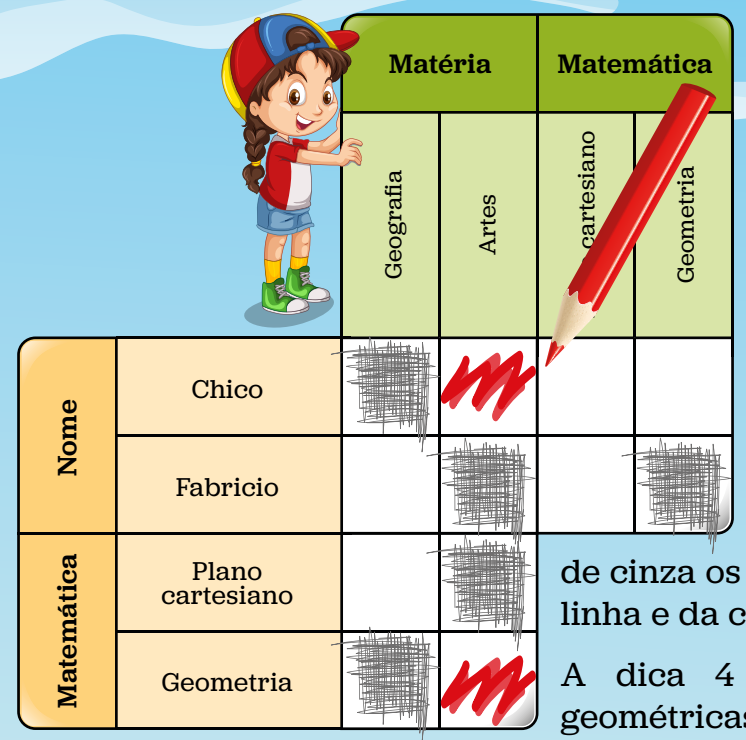

A dica 2 é: Chico é professor de artes. Vamos no diagrama e pintamos de colorido onde tem Chico e artes. Lembrando de pintar de cinza os quadradinhos falsos no resto da linha e da coluna desse quadradinho.

A dica 3 é: o professor de artes usa figuras geométricas. Vamos no diagrama e pintamos de colorido onde tem artes e geometria. Lembrando de pintar de cinza os quadradinhos falsos no resto da linha e da coluna desse quadradinho.

A dica 4 é: Fabricio não usa figuras geométricas. Vamos no diagrama e pintamos de cinza onde tem Fabricio e geometria já que esse quadradinho representa uma frase falsa.

O diagrama está quase completo. Vemos que em algumas linhas e colunas existe apenas um quadradinho sem estar pintado e esses quadradinhos representam frases verdadeiras. Vamos então pintá-lo de colorido para ter nossa resposta. Lembrando de pintar de cinza os quadradinhos falsos no resto da linha e da coluna desse quadradinho.

Agora vemos que o diagrama está completo e vamos escrever as respostas na tabela das respostas.

\section{RESPOSTAS}
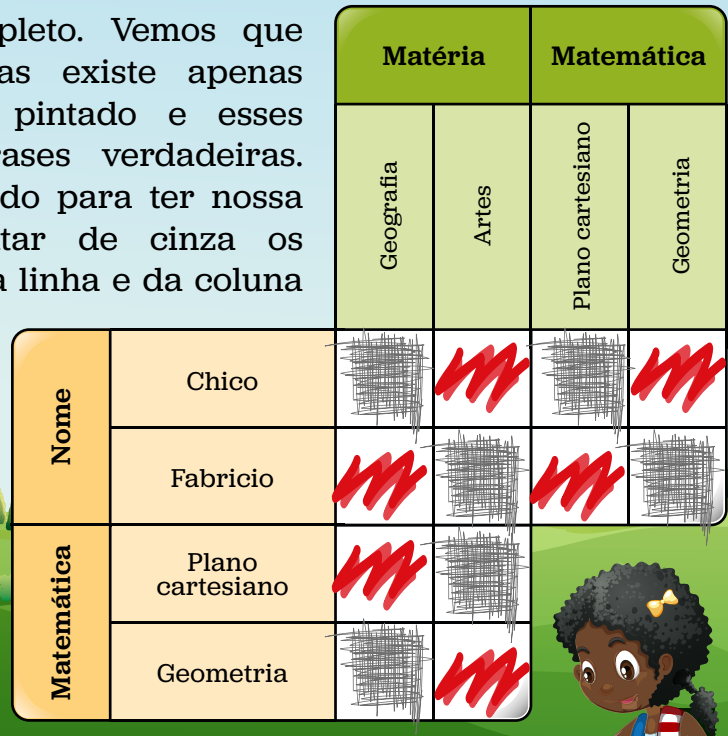

\begin{tabular}{|c|c|}
\hline Nome & Matéria \\
\hline Chico & Artes \\
\hline Fabricio & Geografia \\
\hline
\end{tabular}

Matemática

Geometria 
Murilo e Silvio estão no restaurante conversando. Um deles diz: "Todo dia eu uso a matemática no meu trabalho, eu uso muito ângulos. Sempre fico medindo o ângulo que as articulações dos meus pacientes fazem". O outro disse: "Todo dia eu uso comprimento no meu trabalho, eu corro em uma pista no formato de elipse e sei que a de maior comprimento é a mais longe do centro". Um deles é fisioterapeuta e o outro é corredor olímpico. Siga as dicas para completar o quadro de respostas.

Dica 1: Murilo não é corredor olímpico.

Dica 2: O fisioterapeuta usa ângulos.

Dica 3: Silvio usa comprimento.

Dica 4: O corredor olímpico usa comprimento.

Dica 5: Murilo usa ângulos.

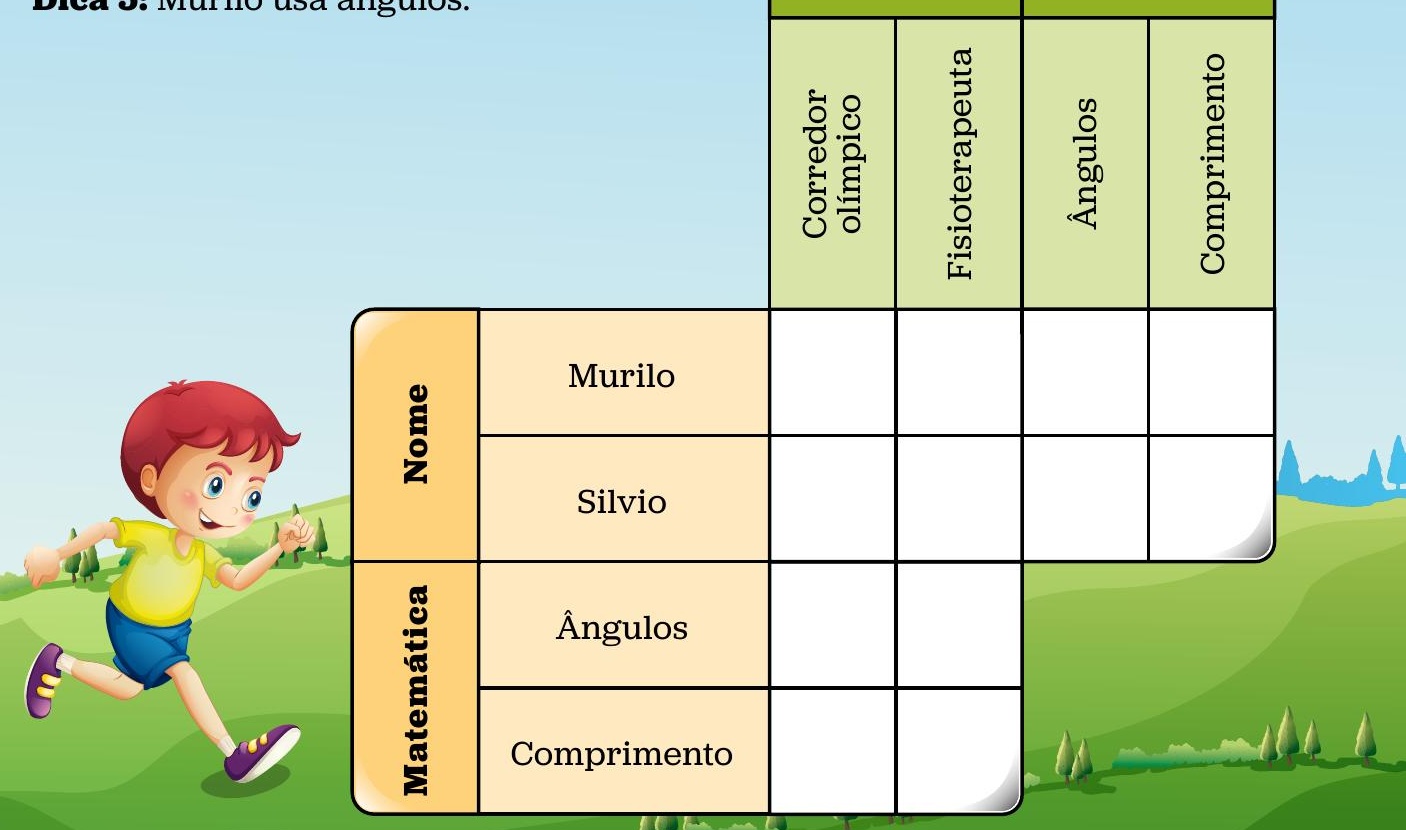

RESPOSTAS

\begin{tabular}{|c|c|c|}
\hline Nome & Profissão & Matemática \\
\hline Murilo & & \\
\hline Silvio & & \\
\hline
\end{tabular}




\section{DESAFIO 2}

Chuck e Norris trabalham no mercado da produção. Em uma conversa um disse ao outro: "Minha balança digital quebrou, tive que usar a antiga e boa regra de 3 para cobrar do meu freguês". O outro respondeu: "Eu uso o cálculo de porcentagem todo dia para saber quanto irei ganhar por mesa que atendo no restaurante". Um deles é garçom e o outro é açougueiro. Siga as dicas para completar o quadro de respostas.

Dica 1: O açougueiro usa regra de três.

Dica 2: Chuck é garçom.

Dica 3: O garçom usa porcentagem.

Dica 4: Norris não usa porcentagem.

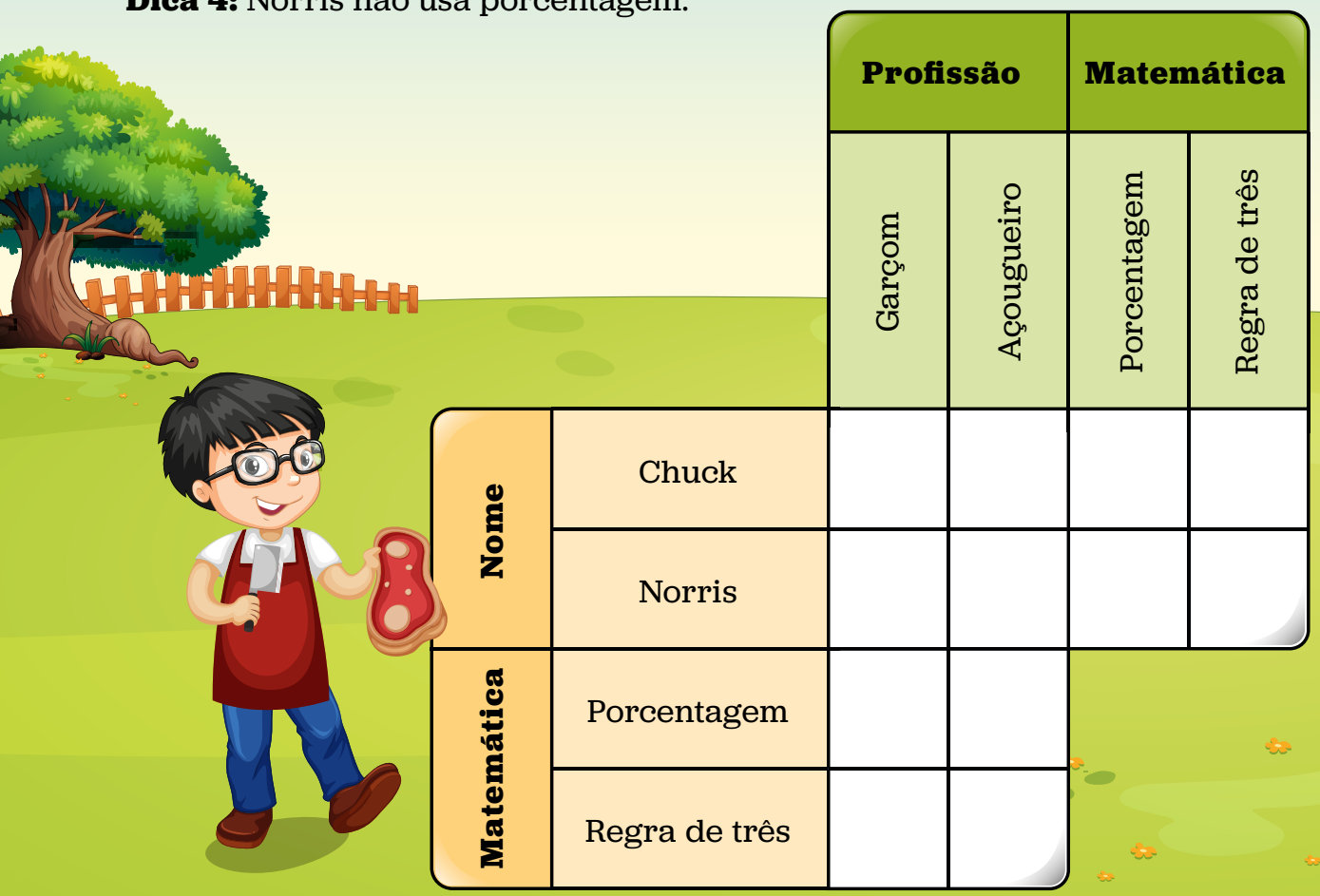

\section{RESPOSTAS}

\begin{tabular}{l} 
RESPOSTAS \\
\begin{tabular}{|l|l|l|}
\hline Nome & Profissão & Matemática \\
\hline Chuck & & \\
\hline 8 Norris & & \\
\hline
\end{tabular} \\
\hline
\end{tabular}




\section{DESAFIO 3}

Julio e Lucas são amigos. Cada um tem uma profissão distinta. Eles usam matemática sempre no seu trabalho. Em uma conversa, um deles disse: "Todo dia eu uso as operações de soma e subtração para dar o troco certo ao passageiro". O outro disse: "Todo dia eu uso frações para saber a quantidade de comida que vou colocar na panela". Um deles é cozinheiro e o outro é cobrador de ônibus. Siga as dicas para completar o quadro de respostas.

Dica 1: Julio usa frações.

Dica 2: Lucas não é cozinheiro.

Dica 3: O cobrador usa as operações.

Dica 4: Quem usa frações é cozinheiro.

Dica 5: Julio não é cobrador.
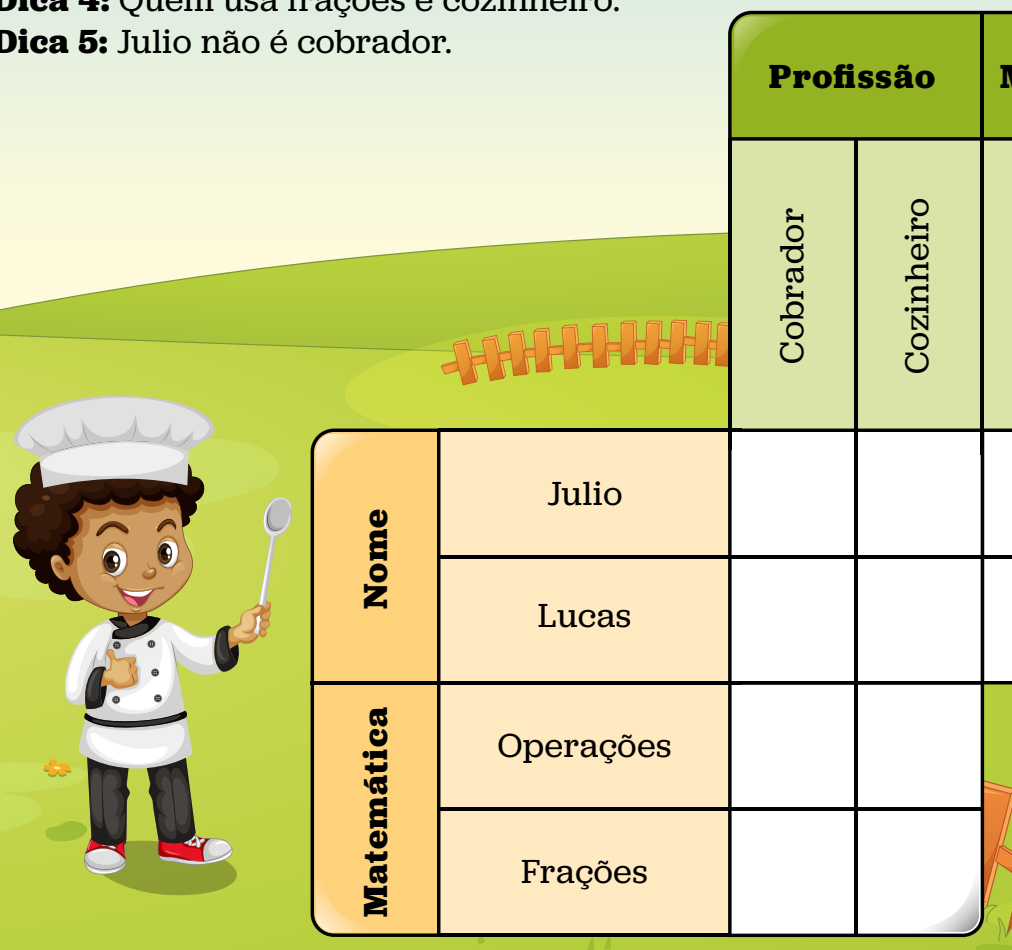

\section{RESPOSTAS}

\begin{tabular}{|c|l|l|}
\hline Nome & Profissão & Matemática \\
\hline Julio & & \\
\hline Lucas & & \\
\hline
\end{tabular}

Matemática 


\section{DESAFIO 4}

Fransikinha e Jumeliça são irmãs e trabalham no mesmo hospital. Na hora do almoço elas conversam e uma disse: "Eu uso proporção para fazer misturas de insulinas para tratamento de pacientes diabéticos", a outra disse: "Eu uso expressão numérica para calcular o IMC (índice de massa corpórea) dos meus pacientes". Uma é enfermeira e a outra nutricionista. Siga as dicas para completar o quadro de respostas.

Dica 1: A enfermeira usa proporção.

Dica 2: Jumeliça é nutricionista.

Dica 3: A nutricionista usa expressão numérica para calcular o IMC.

Dica 4: Fransikinha não usa expressão numérica.
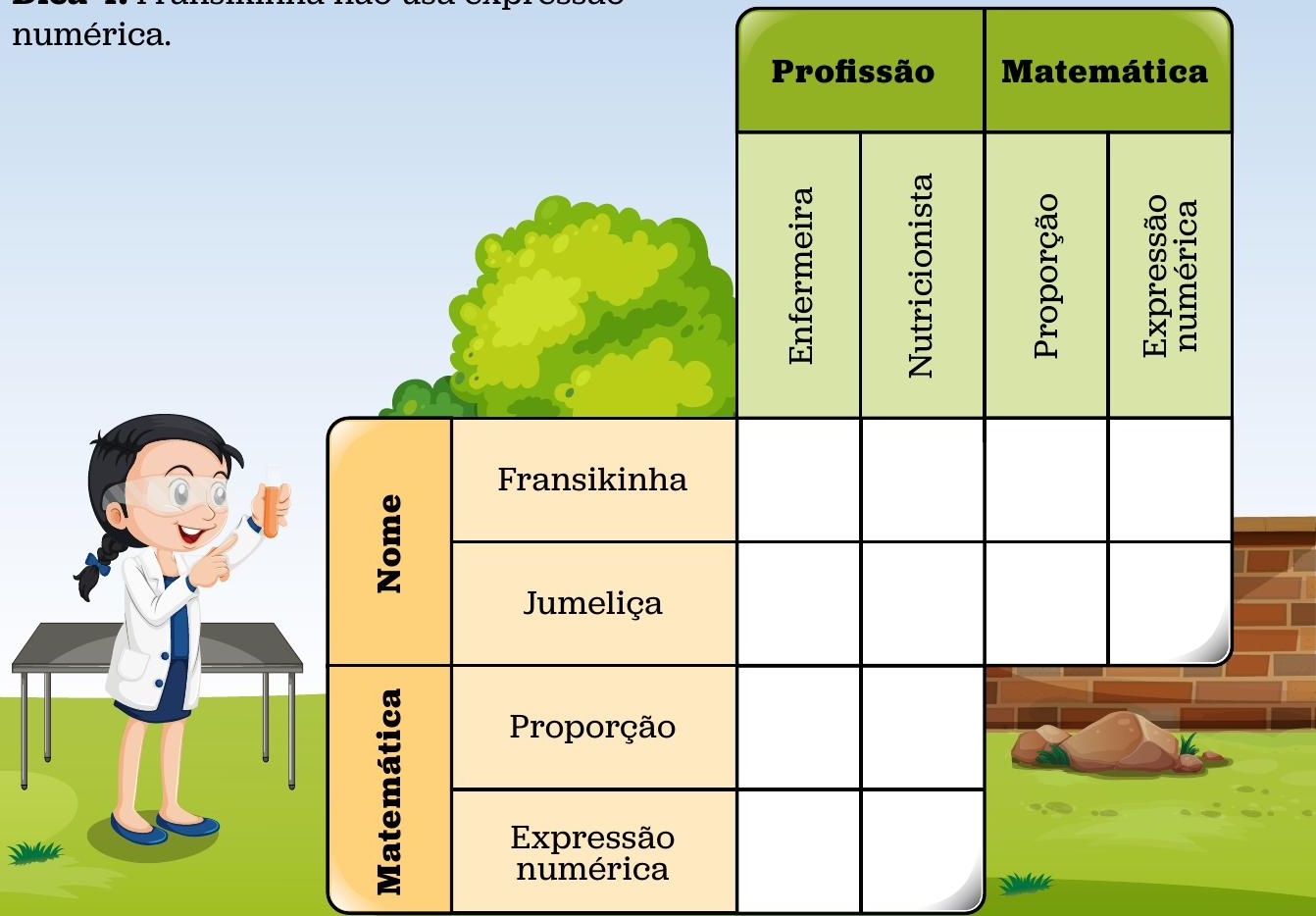

RESPOSTAS

\begin{tabular}{|c|c|c|}
\hline Nome & Profissão & Matemática \\
\hline Fransikinha & & \\
\hline Jumeliça & & \\
\hline
\end{tabular}




\section{DESAFIO 5}

Nicolas e Rafael são companheiros de Empresa. Eles sempre usam matemática nas suas funções. Em uma conversa um deles disse: "Todo dia eu utilizo litros de produtos de limpeza". E o outro disse: "Utilizo operações de adição e multiplicação na gráfica”. Um deles é Assistente de Serviços Gerais e o outro Assistente Gráfico. Siga as dicas para completar o quadro de respostas.

Dica 1: Nicolas faz operações de multiplicação e adição.

Dica 2: Rafael não é Assistente Gráfico.

Dica 3: O Assistente Gráfico usa operações.

Dica 4: Quem usa conversões de litros é Assistente de Serviços Gerais.

Dica 5: Nicolas não usa conversões de litros.

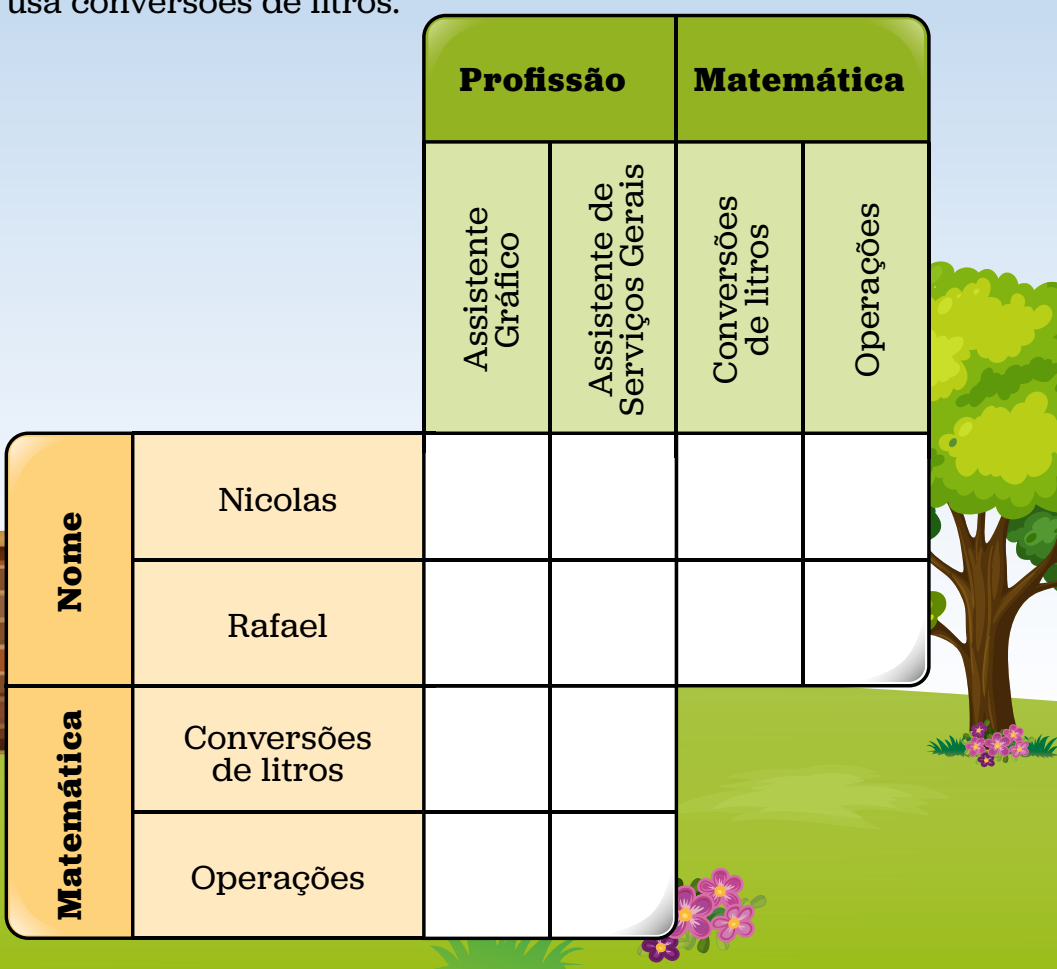

RESPOSTAS

\begin{tabular}{|c|c|c|}
\hline Nome & Profissão & Matemática \\
\hline Nicolas & & \\
\hline Rafael & & \\
\hline
\end{tabular}




\section{DESAFIO}

Demetria e Lola têm profissões diferentes. Certo dia uma delas disse: "Eu uso medidas de litros todos os dias para saber a quantidade de produto que vou colocar no cabelo das minhas clientes." A outra disse: "Eu uso as operações de adição e subtração para calcular o troco certo do meu cliente." Uma delas é cabeleireira e a outra é caixa do mercadinho. Siga as dicas para completar o quadro de respostas.

Dica 1: Demetria não é caixa.

Dica 2: Lola usa operações.

Dica 3: A cabeleireira usa conversão de volumes.

Dica 4: Demetria é cabeleireira.
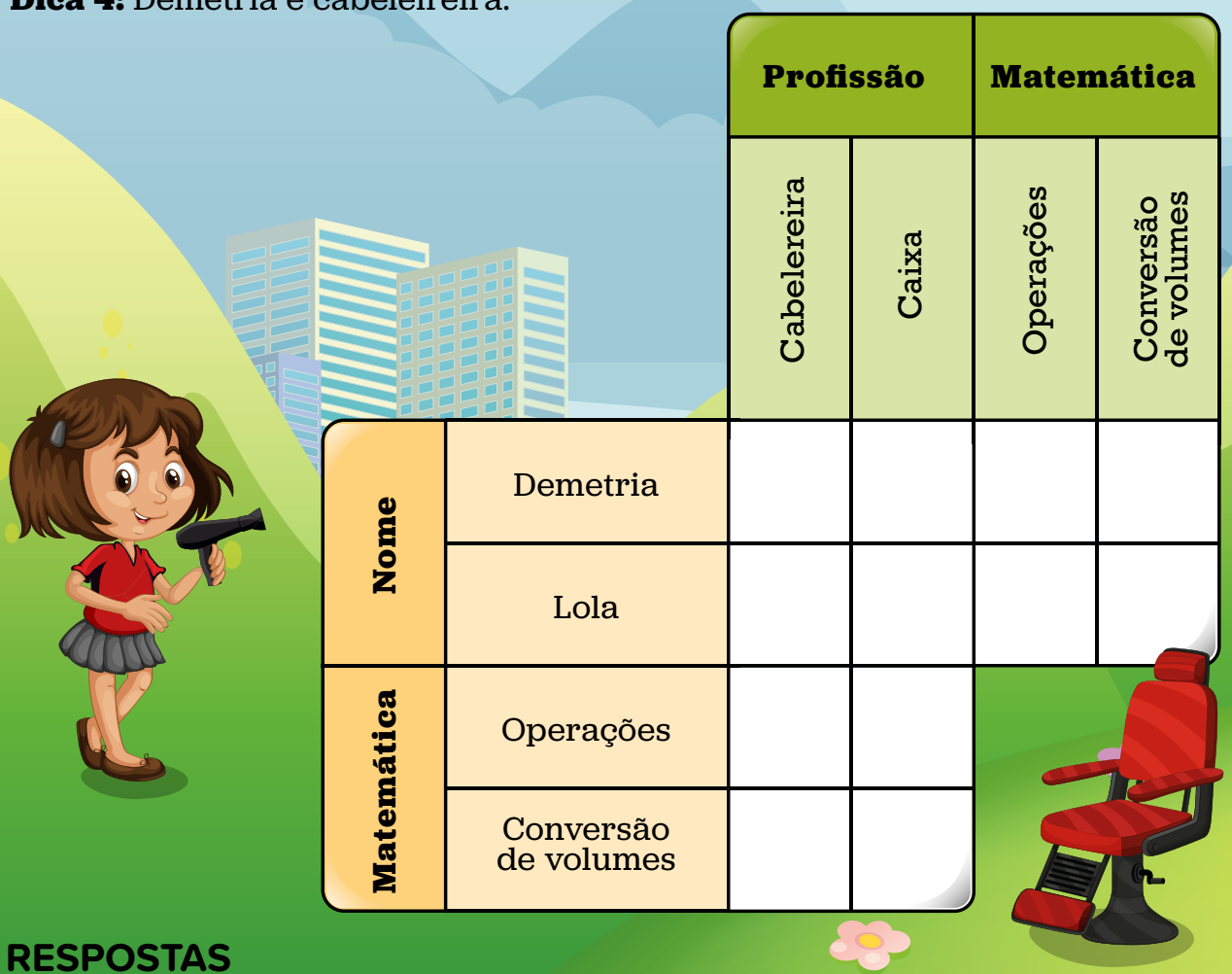

RESPOSTAS

\begin{tabular}{|c|c|c|}
\hline Nome & Profissão & Matemática \\
\hline Demetria & & \\
\hline Lola & & \\
\hline
\end{tabular}




\section{DESAFIO 7}

Ana e Clara pegam sempre o mesmo ônibus para ir ao trabalho. Elas usam matemática todos os dias ao realizar suas tarefas. Certo dia uma delas disse: "Todos os dias eu uso as quatro operações quando registro pagamento de recibos na loteria". E a outra disse: "Todo dia eu utilizo medidores de volume para encher os tanques dos carros". Siga as dicas para completar o quadro de respostas.

Dica 1: Ana trabalha medindo volume para encher tanques.

Dica 2: Clara não é frentista.

Dica 3: A frentista trabalha medindo volumes.

Dica 4: Ana não é caixa da loteria.

Dica 5: Quem usa as quatro operações é caixa da loteria.

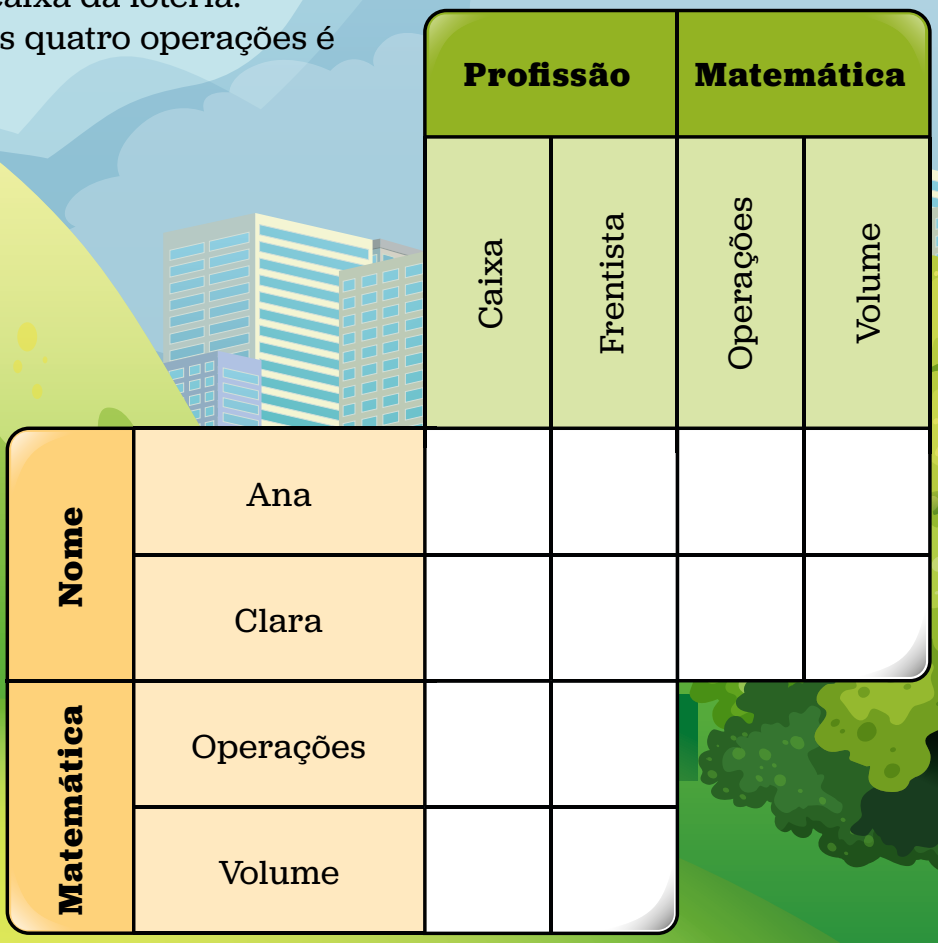

\section{RESPOSTAS}

\begin{tabular}{|c|c|c|}
\hline Nome & Profissão & Matemática \\
\hline Ana & & \\
\hline Clara & & \\
\hline
\end{tabular}




\section{DESAFIO}

Irene e Joaquina são irmãs, cada uma tem uma profissão. Certo dia uma delas disse: "Todo dia eu trabalho com matemática, uso geometria o tempo todo fazendo as telas, os teclados e botões que ficam nos celulares que são formas geométricas também". A outra disse: "Todo dia eu uso múltiplos e divisores para poder falar os horários que meus pacientes devem tomar os remédios". Uma delas é médica e a outra é designer de celulares. Siga as dicas para completar o quadro de respostas.

Dica 1: Irene não é médica.

Dica 2: Joaquina não usa geometria.

Dica 3: Quem usa múltiplos é médico.

Dica 4: Joaquina usa múltiplos.

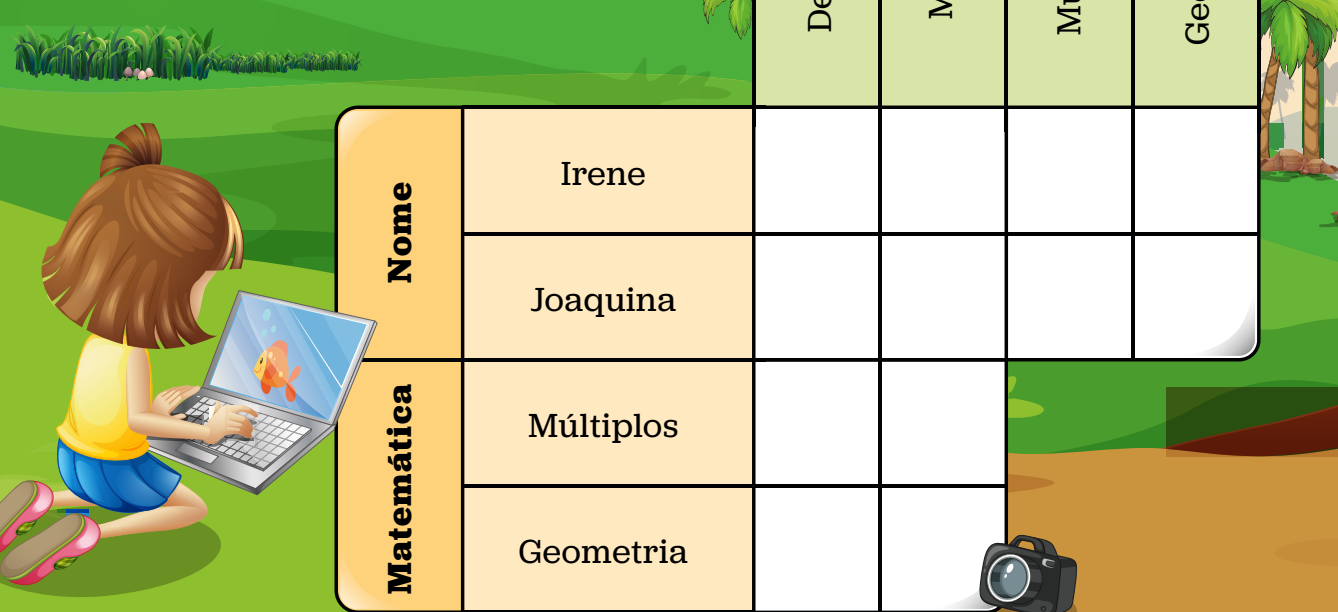

RESPOSTAS

\begin{tabular}{|c|c|c|}
\hline Nome & Profissão & Matemática \\
\hline Irene & & \\
\hline Joaquina & & \\
\hline
\end{tabular}




\section{DESAFIO 9}

Genura e Paula estão falando sobre matemática nas suas profissões. Uma delas disse: "Eu uso porcentagem para calcular os juros que as pessoas vão ter se atrasarem o pagamento". A outra disse: "Eu uso frações para dividir a pizza dos fregueses". Uma delas é contadora e a outra é pizzaiola. Siga as dicas para completar o quadro de respostas.

Dica 1: Paula não usa frações.

Dica 2: Genura é pizzaiola.

Dica 3: A contadora usa porcentagem.

Dica 4: A pizzaiola usa frações.

Dica 5: Paula não é pizzaiola.

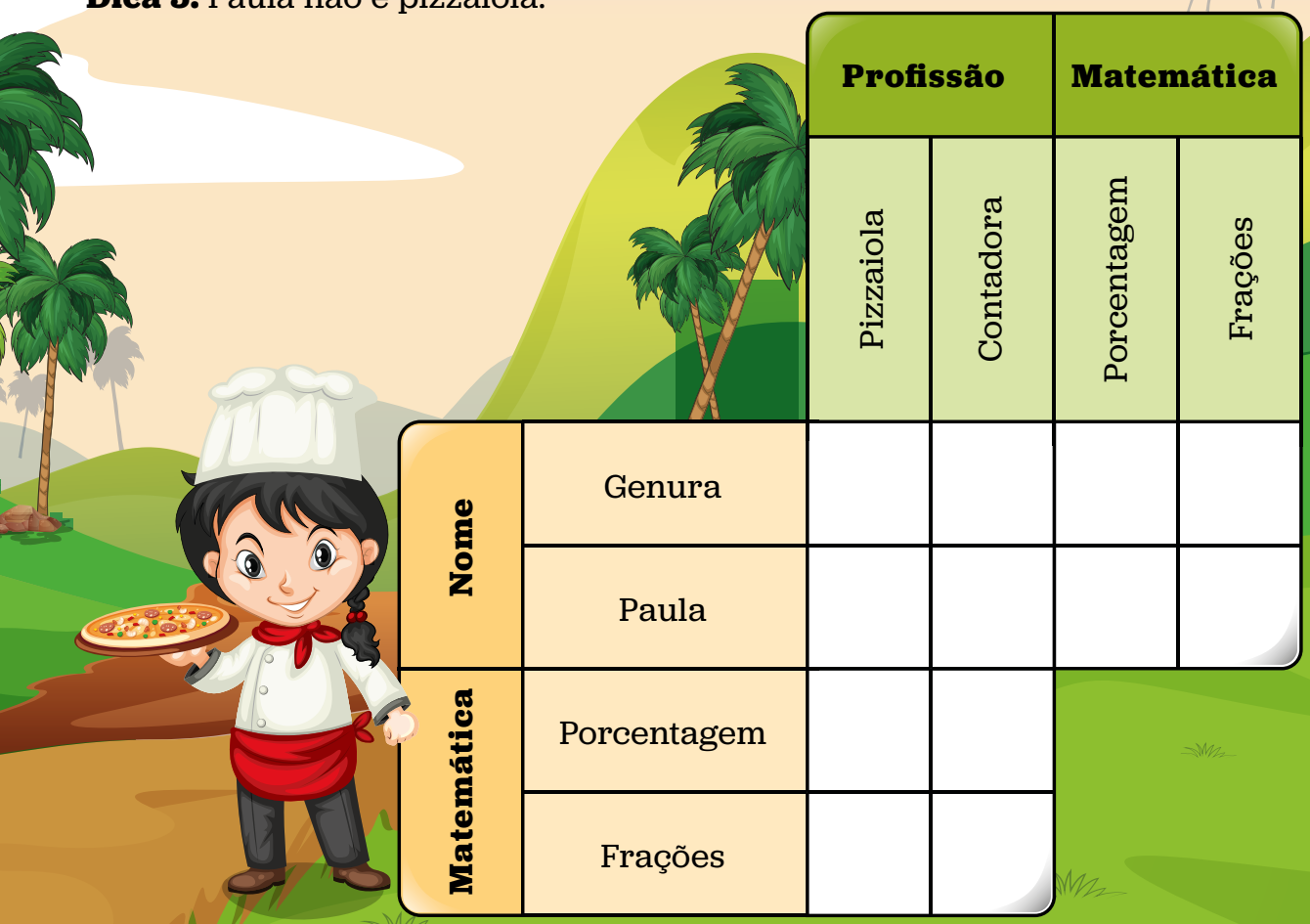

RESPOSTAS

\begin{tabular}{|c|c|c|}
\hline Nome & Profissão & Matemática \\
\hline Genura & & \\
\hline Paula & & \\
\hline
\end{tabular}




\section{PALAVRAS CRUZADAS}

Relacione as frases com as profissões abaixo para completar a cruzadinha.

Policial

Empresário

Psicólogo

Profissões

Médico

Cantor

Modelo Advogado

Cientista

Bombeiro

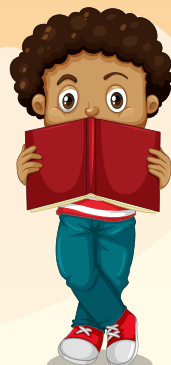

Advogado
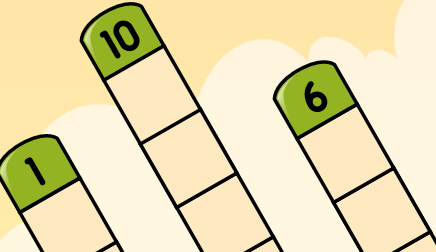

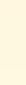
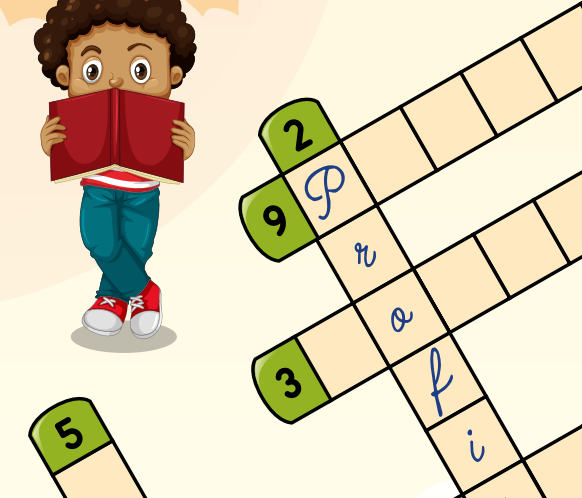

(9)

r

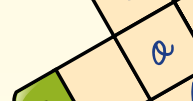

i

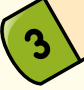

a 
5 Ao efetuar um cálculo de dosagem de medicamento, é comum levar em consideração somente a massa corporal do paciente, pois a dosagem é determinada dependendo da massa corporal da pessoa, assim existe uma proporção entre massa corporal e dosagem.

6 A depender da forma como uma corda do violão vibra, temos um som diferente, cada som pode ser representado por uma fração, assim fazem as músicas nessa profissão.

7 Uma determinada profissão faz uso de frações quando há uma repartição de heranças, partilhas e valores. Em caso de divórcio, faz uso de proporções para definir com quem fica a maior parte da venda da casa, do apartamento e do carro comprado pelo casal.

8 Ao inaugurar certas companhias é comum os sócios fazerem um breve estudo sobre a função "gasto" e "lucro", para saber a média de porcentagem de lucro que vão ter com suas parcerias.

9 Ao fazer um estudo que envolve número de jovens com depressão no Brasil são realizadas entrevistas e calcula-se porcentagens. Depois disto são feitos gráficos e análise dos motivos que ocasionam a depressão.

10 o uso da estatística é algo muito importante para sabermos em quais regiões ocorrem maior número de assaltos, com isso pode-se disponibilizar mais veículos para tal região.

Qual(is) profissão(ões) do jogo você conhece?

O que faz cada uma dessas profissões que você citou na pergunta anterior?

Qual é a matemática utilizada nessas profissões que você citou?

Qual é a profissão que você gostaria de estudar na sala de aula? 


\section{CAÇA PALAVRAS}

Encontre as palavras escondidas

J H H OLDAFHADFDFLLDOPLOLHAB A B FF SFFU Y C O G D I R E T OR DEC I N E M A D R OL D O B A D V O G A D OR O O

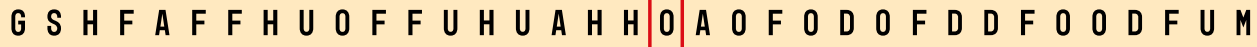
A S O D J S D O B G A D B O B J O O F J J DE M PRE SÁR I O DRE

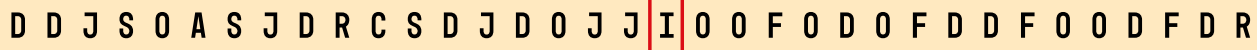
OGCCT T C CRUOCFCFCCFAS DES I GNDEGAMEAAC R D A A A E A A D E Z A D A D Y A A S A B A D F F S F D Y J LF F W I $G$ E B T C Y T B S T I T S B S Y B B Õ C B F S S D A A D O O O O A D E A R O D O V I ÁR I O N I C Y C D D Y E C Y C C A S O J K URA H S E N T T E E A E O Y Y O A H O C I E N T I S T A O E L T U T Y O Y R R A T T O A D D D D A O S A O E S DLFR Y O O B O I B E N G E N H E I R O I L T S L O A L T S T A O

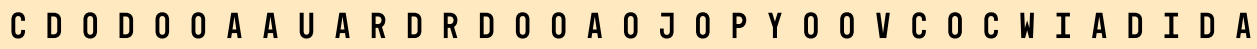
A K G S A U C C C C O U H A G U M U UAS OLAEAN NE S C G O D C T A R C C R A A A ALDGWRR ORR C I UB J T T AEETCDLKA I D U A A D R R N R OR S E UDDDKACR D O E I D I Y A B E B A R O O M T R A A A T A A A S E A A E A B R Ó D U T R O D I O U O O D D D A L C É I A W M M O M J C D Y E W L W E A L A D A I L K O O B R R U O M B N D O ME A A R A OC G O A E O E O M OWR C N B A KL D B A D C A D U I L A E A U E A T E DE AE A E A A GE B C Á D DR ORRRR N A UN C B E Y A P O L I C I AL YE Y C A O E UAR U O Y O UT UBER DR ODNOAR D N A E D D N OA OA A C Y B Y I D C C R A DCC C R A RE P O R T ER E S P ORT I V ORRACOUOOR N T TEE C E A A

Jogador

Cientista

Médico

Rodoviário

Veterinário
Diretor de cinema Modelo Cozinheiro Cantor Policial Psicólogo
Engenheiro Advogado Comerciante Repórter esportivo
Empresário

Design de game Jornalista Youtuber 


\section{ANOTAÇÕES}

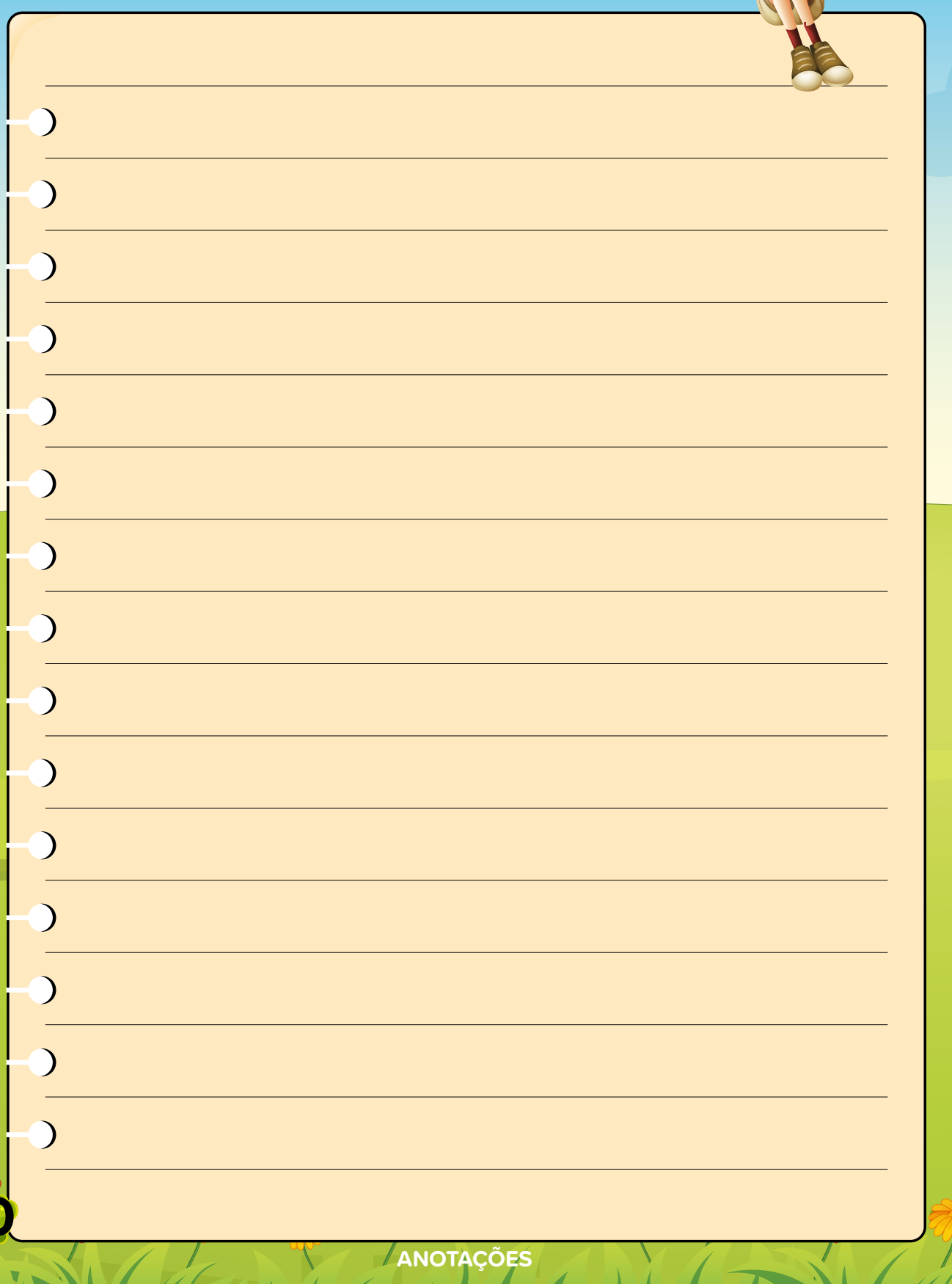




\section{RESPOSTAS}

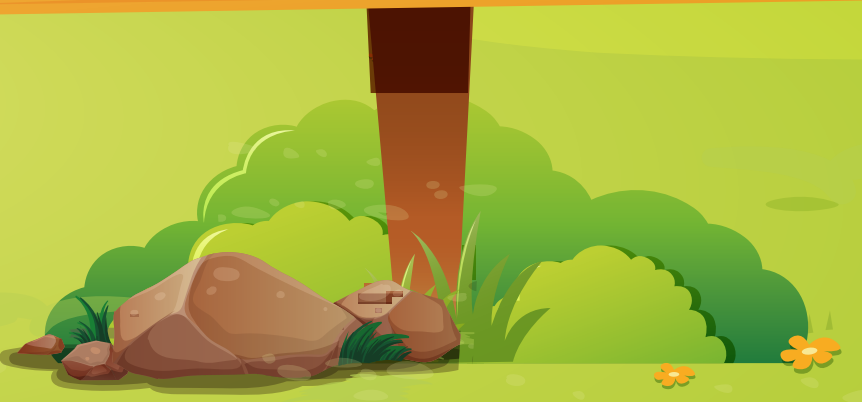




\section{DESAFIO 1}

Murilo não é corredor (dica 1). O fisioterapeuta usa ângulos (dica 2). Silvio usa comprimento (dica 3). O corredor olímpico usa comprimento (dica 4). Murilo usa ângulos (dica 5). Murilo que é fisioterapeuta (pois não é corredor) usa ângulos. Por eliminação, Silvio é corredor e usa comprimento.

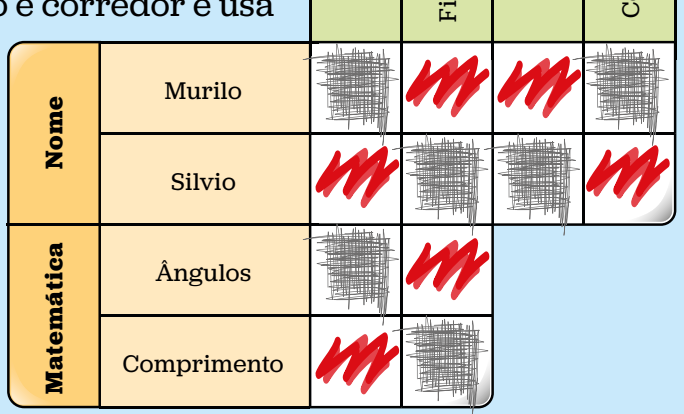

\section{DESAFIO 2}

O açougueiro usa regra de três (dica 1). Chuck é garçom (dica 2). O garçom usa porcentagem. Norris não usa porcentagem (dica 4). Pela dica 3 , Chuck é garçom e usa porcentagem. Por eliminação, Norris é açougueiro e usa regra de três.

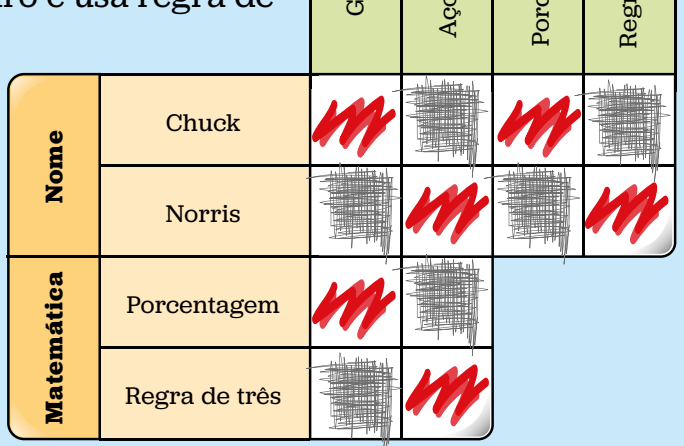




\section{DESAFIO 3}

Julio usa frações (dica 1). Lucas não é cozinheiro (dica 2). O cobrador usa as operações (dica 3). Quem usa frações é cozinheiro (dica 4). Julio não é cobrador (dica 5). Pela dica 4, Julio é cozinheiro e usa frações. Por eliminação, Lucas é cobrador e usa as operações.

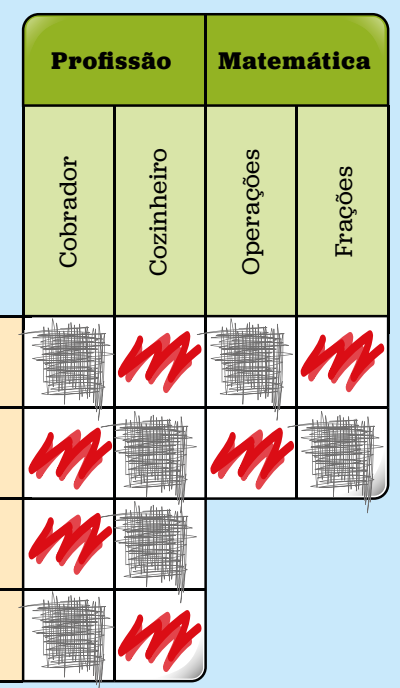

\section{DESAFIO 4}

A enfermeira usa proporção (dica 1). Jumeliça é nutricionista (dica 2). A nutricionista usa expressão numérica para calcular o IMC (dica 3). Fransikinha não usa expressão numérica (dica 4). Pela dica 3, Jumeliça é nutricionista e usa expressão numérica. Por eliminação, Fransikinha é enfermeira e usa proporção.
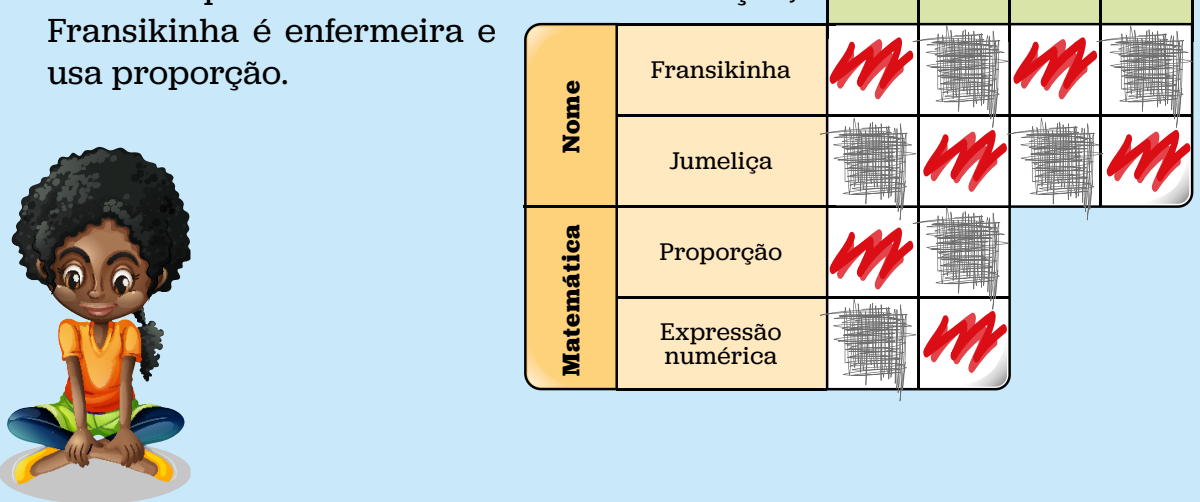


\section{DESAFIO 5}

Nicolas faz operações de multiplicação e adição (dica 1). Rafael não é assistente gráfico (dica 2). O assistente gráfico usa operações (dica 3). Quem usa conversões de litros é assistente de serviços gerais (dica 4). Nicolas não usa conversões de litros (dica 5). Pela dica 4, Rafael é assistente de serviços gerais (pois não é assistente gráfico) e usa conversões de litros. Pela dica 3, Nicolas é assistente gráfico e usa operações.

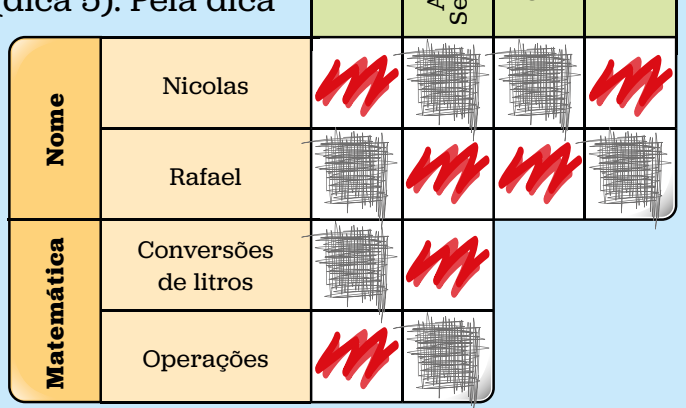

\section{DESAFIO 6}

Demetria não é caixa (dica 1). Lola usa operações (dica 2). A cabelereira usa conversão de volumes (dica 3). Demetria é cabelereira (dica 4). Pela dica 3, Demetria é cabelereira e usa conversão. Por eliminação, Lola é caixa e usa operações.
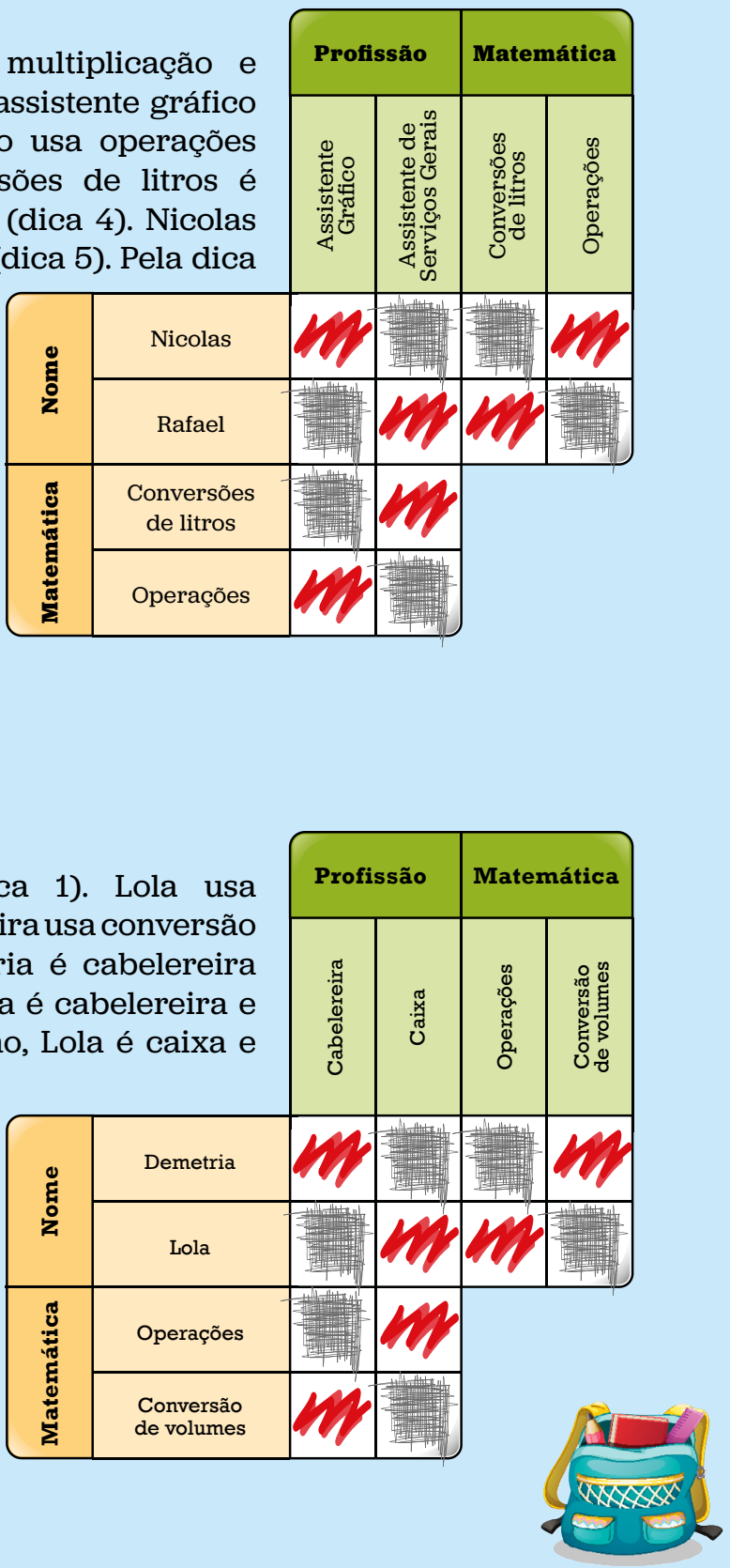


\section{DESAFIO 7}

Ana trabalha medindo volume para encher tanques (dica 1). Clara não é frentista (dica 2). A frentista trabalha medindo volumes (dica 3). Ana não é caixa da loteria (dica 4). Quem usa as quatro operações é caixa da loteria (dica 5). Pela dica 3, Ana é frentista e trabalha medindo volumes. Por eliminação, Clara é caixa da loteria e usa as quatro operações.

\section{DESAFIO 8}

Irene não é médica (dica 1). Joaquina não usa geometria (dica 2). Quem usa múltiplos é médica (dica 3). Joaquina usa múltiplos (dica 4). Irene é designer (pois não é médica) e por eliminação, usa geometria. Pela dica 3, Joaquina é médica e usa múltiplos.

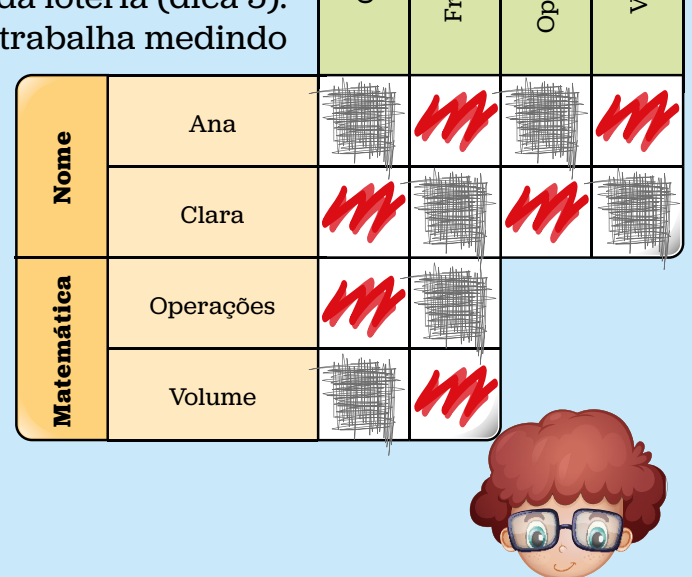

\begin{tabular}{|l|l|}
\hline Profissão & Matemática \\
\hline
\end{tabular}

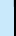

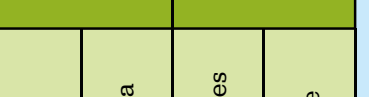




\section{DESAFIO 9}

Paula não usa frações (dica 1). Genura é pizzaiola (dica2). A contadorausa porcentagem (dica 3). A pizzaiola usa frações (dica 4). Paula não é pizzaiola (dica 5). Pela dica 4, Genura é pizzaiola e usa frações. Por eliminação, Paula é contadora e usa porcentagem.

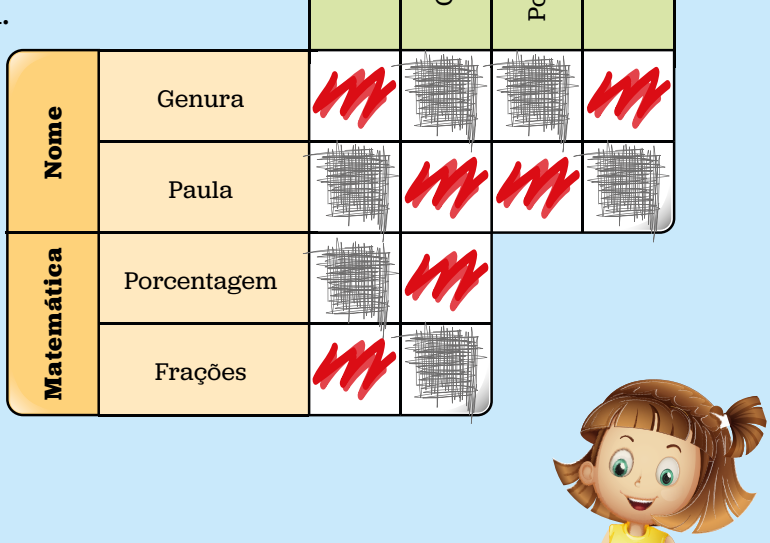

\section{DESAFIO 10}

O fotógrafo usa proporção (dica 1). O jardineiro não é Guilherme (dica 2). Marcos não é fotógrafo (dica 3). Marcos usa geometria (dica 4). Guilherme é fotógrafo (pois não é jardineiro) e pela dica 1, usa proporção. Por eliminação, Marcos é jardineiro e usa geometria.

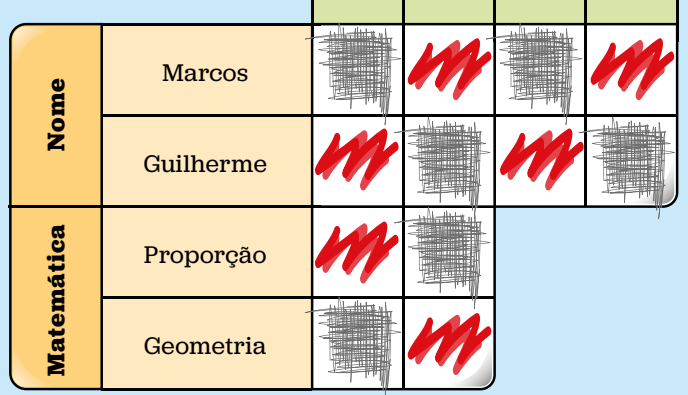




\section{PALAVRAS CRUZADAS}

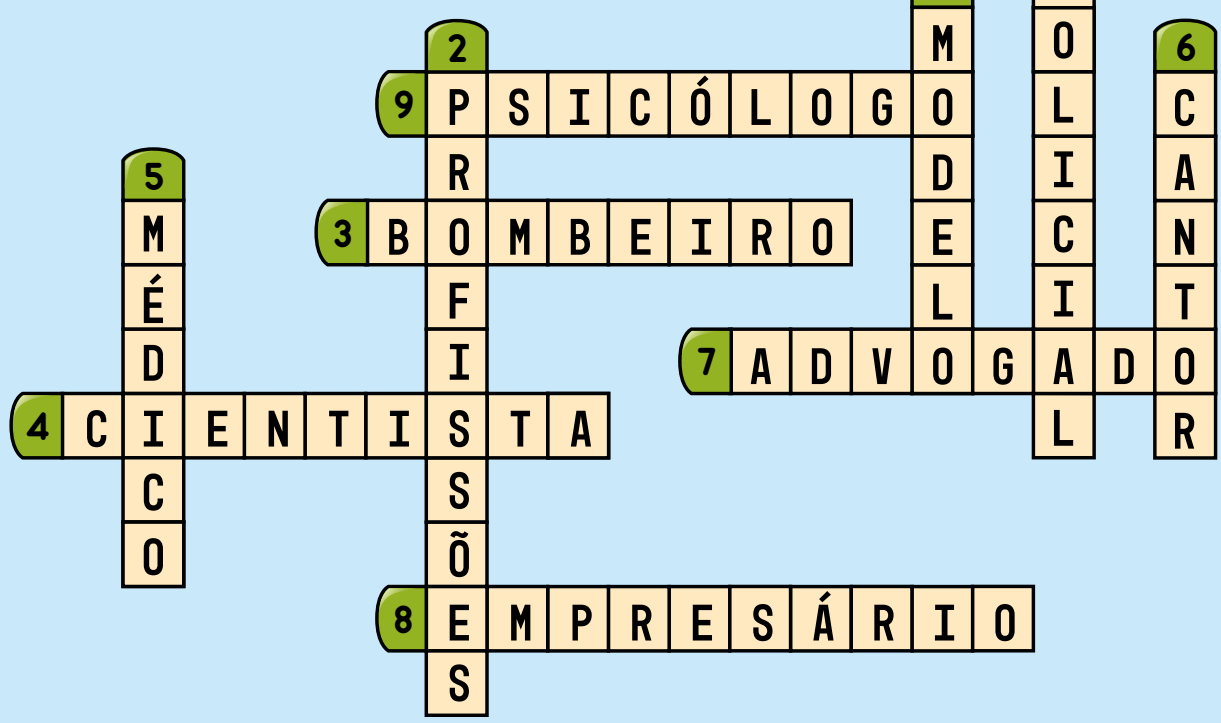

\section{CAÇA PALAVRAS}

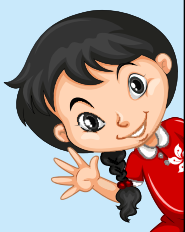

JH H OLDAFHADFDFLLDOPLOLHA B A B FFSFFUYC 0 G D I RE T OR DEC I NEMAD R O L D O BA D V O G A D OR O 0 $G$ S H F A F F H UOFFUHUAH HOAOFODOFDDFOODFUM A S O D J S D O B G A D B O B J O O F J J DE E M PRE SA A R I OD D R E

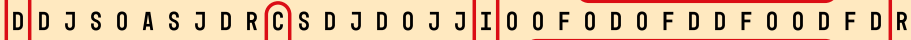
OG C C T T C C R U OCF CFCCF T TEESIG NDEGAMEA A C R D A A A E A A D E Z A D A D Y A A S A B A D F F S F D Y J L F F W I G E B T C Y T B S T I T S B S Y B B Ö C B F S S D A A D 0 O RODOCOVIA T T E E A E O Y O A H O A O A A L Y S Y O C O A C F O A R N J G C Y T C I E N T I S T A O OEL T U T Y O Y R R A T T O A D D D D A O S S A O S D L F R Y O O O B O I BEN GENHE I R OI L T S L O A L T S T A O C D O D O O A A U A R D R D O O A A O J OAPA A K K G S A U C C C C O U H A G U M U U A S O L A E A A N N E S C C G O D C T A R C C R A A A A L L D G W R R I D U A A D R R N $\begin{array}{lll}0 & 0 \\ M & T & R\end{array}$ L C É I A W M M O M J C D Y E W L W E A L A D A I L K O O B B R R U O M B N D O M E A A R A O C G O A E O E O M O W R C N B A K L D B A D C A D U I L A E A U E A T E D E A E A E A A G E B C ÁA D D R O R R R R N A U N C B E Y AP O L I C I A L Y E Y C A O E U A R U OYYOUT T U B E R DROD N OA R D N A E D D N OA O A A C Y B Y I D C C R A D C C R A REPORTERESPORTIVORRACOUOOR N T TEECEA A 


\section{REFERÊNCIAS}

BRASIL, Secretaria de Educação Fundamental. Parâmetros Curriculares Nacionais: terceiro e quarto ciclos do ensino fundamental: uma introdução aos parâmetros curriculares nacionais / Secretaria de Educação Fundamental. Brasília: MEC/SEF, 1998.

, Secretaria de Educação Fundamental. Parâmetros Curriculares Nacionais: matemática / Secretaria de Educação Fundamental. Brasília: MEC/SEF, 1998.

- Ministério da Educação e do Desporto. Secretaria de Educação Fundamental. Parâmetros Curriculares Nacionais: matemática (primeiro e segundo ciclos). Brasília, $199 \%$.

BZUNECK, J. A. A motivação do aluno: Aspectos introdutórios. In: BUROCHOVITCH, E.; BZUNECK, J. A. (Orgs.). Motivação do aluno: Contribuições da psicologia contemporânea. Petrópolis: Editora Vozes, 2001.

MOGNON, J. F. Motivação para aprender na escola. Psico-USF, v. 15, n. 2 , p. 273-275, mai./ago. 2010.Universidade São Francisco, Itatiba, Brasil, 2010.

NEVES, E. R. C.; BORUCHOVITCH, E. A Motivação de Alunos no Contexto da Progressão Continuada. Psicologia: Teoria e Pesquisa Jan-Abr 2004, Vol. 20, n. 1, pp. 077-085, 2010.

PEQUENO, M. J. S.; SILVA, C. S. S. O PROJETO "MATEMÁtiCA, SAÚdE E QUALIDADE DE VIDA". II CONEDU - Congresso Nacional de Educação, 2015.

SCHEFFER, N. F.; BATTISTI, S. A EXTENSÃO EM MATEMÁTICA: UMA PRÁtICA DESENVOLVIDA NA COMUNIDADE ESCOLAR. II CNEM Congresso Nacional de Educação Matemática, 2011.

SILVA, E. F. S. e; ALBUQUERQUE, E. S. da C.; SANTOS, V. de O. Produtos educacionais voltados para a matemática no dia a dia: "Geocampo" e "Matemática nas profissões". BoEM, Joinville, v. 6, n. 10, p. 276-293, ago 2018.

SILVA, A. Economia de Maceió: diagnóstico e propostas para a construção de uma nova realidade. Brasília. IPEA: EDUFAL, 2013.

TARDIF, M. Saberes Docentes e Formação Profissional. 13. ed. Petrópolis: Vozes, 2012. 


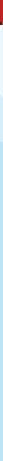


